REVIEW ARTICLE

\title{
Sleep Apnoea: Impact on safety and psychosocial functions
}

\section{Dang, D Cunnington}

Melbourne Sleep Disorders Centre, Australia $\ldots \ldots \ldots \ldots \ldots \ldots \ldots \ldots \ldots \ldots \ldots$

Indian J Sleep Med 2009; 4.3, 95-99

\begin{abstract}
Sleep apnoea is a common condition within the community. The consequences of untreated sleep apnoea are far-reaching and they include cardiovascular and cerebrovascular morbidity and mortality, neurocognitive impairment, increased risk of motor vehicle accidents, occupational injuries, lower quality of life (QOL), and mood disorders. It is an important public safety issue in light of its prevalence in certain subgroups. Untreated sleep apnoea has substantial safety and psychosocial impairments, which translate to major health care costs. Continuous positive airway pressure (CPAP) treatment for sleep apnoea has been shown to have a positive impact on subjective quality of life and depression, and is cost effective.
\end{abstract}

Keywords: obstructive sleep apnoea, safety, psychosocial function, quality of life, continuous positive airway pressure

\section{Introduction}

S leep apnoea is characterised by the recurrent reduction in airflow or cessation of breathing during periods of sleep, with resultant arousals from the sleep state. It is prevalent in $4 \%$ of men and $2 \%$ of women in middle age ${ }^{1}$. Obstructive sleep apnoea (OSA) is often used interchangeably with the term obstructive sleep apnoea-hypopnoea (OSAH), and is considered the obstructive sleep apnoea syndrome (OSAS) when it is when combined with excessive daytime sleepiness. In the Indian population the prevalence of OSAS in males aged between 35-65 years is 7.5\% ${ }^{2}$, whilst Sharma et al established the prevalence of OSA and OSAS at $13.7 \%$ and $3.6 \%$ respectively in men, and $4.96 \%$ and $2.03 \%$ respectively in women ${ }^{3}$. This remarkably similar prevalence was derived after accounting for selection

Address for Correspondence

Dien Dang, Melbourne Sleep Disorders Centre Suite 508, 100 Victoria Parade

East Melbourne, Victoria, Australia 3002

Email:dien@msdc.com.au biases in terms of gender and socioeconomic class, despite differences in cephalometric variables and obesity rates ${ }^{3}$. Sleep apnoea is underdiagnosed and undertreated in the community ${ }^{4}$.

Repeated interruptions to breathing, whether it be from a physical block as in obstructive sleep apnoea, or an absence of respiratory effort in cases of central sleep apnoea, has cognitive and physiological consequences. Reported neurocognitive impairments include deficits in vigilance, concentration, alertness, short and long term memory, global intellectual dysfunction and executive functions $s^{5}$. Published literature appears to show a limited consensus regarding the type and severity of dysfunction from sleep apnoea.

Whilst some studies have shown those with OSA who subsequently received CPAP intervention fared better in tests of vigilance and alertness compared to those without treatment ${ }^{6}$, others such as Gast et al have found few CPAP-related improvements ${ }^{7}$. These inconsistent findings maybe possibly be explained by the partial nature of sleep deprivation in sleep apnoea, the development of executive coping strategies, a lack of standardized tests

Indian Journal of Sleep Medicine (IJSM), Vol. 4, No. 3, 2009 
specifically targeted at CPAP treatment outcomes, or a longer period of time needed for neurocognitive changes to be rectified.

\section{Sleep apnoea, motor vehicle accidents and occupational injury}

Driving a motor vehicle is an intricate task comprised of many skills, each of which can be adversely influenced by many conditions including sleep apnoea, alcohol (implicated in $32 \%$ of all USA traffic fatalities ${ }^{8}$ ), excessive speed (a cofactor in $31 \%$ of all fatal crashes $^{9}$ ), road circumstances, and driver experience. While crash statistics and their predisposing factors are heterogeneous and possibly inferential in nature, the abundance of epidemiological and investigational data recently reviewed by George has consistently supported findings that untreated sleep apnoea increases the risk for motor vehicle accidents from between two- and tenfold compared to control groups ${ }^{10}$, presumably from the same neurocognitive deficits mentioned earlier. The subpopulations of commercial drivers have a higher prevalence of sleep apnoea, obesity, sleepiness, and rate of motor vehicle accidents ${ }^{11}$.

Although Indian road traffic statistics are less comprehensive, the total number of lives lost from traffic accidents is just as compelling - an estimated 110,000 road-accident related deaths, 2.5 million hospitalisations, and an economic loss of 3\% of GDP for the year $2005^{12}$. More precise measures of the risk of car accidents associated with sleep apnoea is complicated by a potential bias towards retrospective underreporting of sleepiness and fatigue in collision circumstances, inability to remove other influencing factors such as individual work schedules, medications, road familiarity and driver skill.

Treatment with CPAP in drivers with sleep apnoea has been shown to decrease motor vehicle accident rates to rates seen in the general driving population ${ }^{13}$. On the base-case analysis of newly diagnosed OSAH sufferers in the US carried out by Ayas et al., treatment of sleep apnoea with CPAP reduced the rate of collisions by a factor of seven compared to no CPAP ${ }^{14}$.

Similarly, as a consequence of greater inattention and reduced vigilance the risk of being involved in an occupational accident is at least twice in male heavy snorers with a $50 \%$ increase in men with OSAS, and at least three times as high for females with heavy snoring and OSAS ${ }^{15}$. Prospective studies have also demonstrated similar odds ratios towards occupational injuries in sleepy snoring males ${ }^{16}$, as well as risk of work disability in both genders with an OSAS diagnosis ${ }^{17}$.

Although the benefits in relation to occupational injury have not been studied as extensively as motor vehicle accidents, similar statistical gains might be deduced given that the same cognitive returns will be made in these sleep apnoea candidates.

\section{Sleep apnoea, quality of life and depression}

The important associations between poor sleep, quality of life (QOL), attention-to-task, and mood disorders have been explored from the psychiatric, neurological, epidemiological and respiratory-sleep perspectives. Severe sleep apnoea sufferers have a reduced QOL compared to normal individuals as measured by the generic Medical Outcomes Study Short-Form (36-item) Health Survey $(\mathrm{SF}-36)^{18}$.

These general quality of life questionnaires are often negatively influenced by the symptoms of excessive daytime sleepiness, altered perception of functional and emotional well-being ${ }^{19}$. Disease-specific assessment tools as such as the Functional Outcomes of Sleep Questionnaire (FOSQ) have been shown to improve with sleep apnoea treatment, suggesting construct validity of this measure. FOSQ contains 30 items divided into five scales - activity level, vigilance, intimacy and sexual relationships, general productivity, and social outcome $e^{20}$.

Within the FOSQ's five scales are indirect measures of an individual's perceived neurocognitive ability (in particular the concepts of vigilance and attention to task), the negative impact of which has already been previously delineated in consideration to motor vehicle collisions and occupational risk. These functional impairments have also been found to be in line with measures of sleep propensity as measured by the Epworth sleepiness scale ${ }^{18}$.

Disordered sleep can be seen to modulate depression and vice versa. Sleep disruption is a common symptom in those with depression, reflected by their inclusion as a DSM-IV diagnostic criterion. Conversely many patients with OSA also have depressive symptoms ${ }^{21-23}$ and some studies have placed the prevalence at up to $48 \%{ }^{18}$, but the accepted general prevalence of depression in this population remains unclear ${ }^{24}$.

In a cross-sectional telephone survey of 18,980 
individuals performed by Ohayon, $0.8 \%$ of people had both a breathing-related sleep disorder and a major depressive disorder ${ }^{25}$. The identification of a breathingrelated sleep disorder also indicated a $20 \%$ chance of having major depression as a co-condition and vice versa, and awareness of this association is recommended ${ }^{25}$. A similar longitudinal dose-response association between sleep-related breathing disorder and depression supports a causal link between these conditions ${ }^{26}$. QOL also correlates with the Zung self-rated depression scale in sleep apnoea patients ${ }^{18}$. A significantly higher prevalence of anxiety disorders, posttraumatic stress disorder, psychosis, and dementia were also found in sleep apnoea patients ${ }^{27}$.

Treating sleep apnoea with CPAP has been seen in measures of subjective sleepiness with the ESS ${ }^{24,28}$, general QOL measures (such as the SF-36) and in disease-specific measures of QOL $(\mathrm{FOSQ})^{28}$. Improvements in attention to task and neurocognitive tests following CPAP treatment are less forthcoming, made more difficult by the lack of differentiation on the basis of sleep apnoea severity in these studies, as well as a lack of an accepted assessment protocol to gauge improvements ${ }^{24}$. Despite this, the economic and social burden of mood disorders and the ensuing quality of life would imply that this relationship warrants further inquiry.

\section{The economic cost}

Although sleep apnoea has a considerable impact on safety and psychosocial functioning, using economic terms to measure this impact has several benefits. The sum-total of healthcare and non-healthcare expenditure incurred by a condition in one individual can be extrapolated to the wider community. This allows for comparisons between different social groups and amongst different countries, and permits an appraisal of treatments through the demonstration of cost-effectiveness.

The economic impact of untreated sleep apnoea begins many years prior to the time of diagnosis and treatment ${ }^{29,30,31}$. Kapur et al demonstrated that sleep apnoea sufferers accumulated on average twice as much in healthcare expenses over the year before their treatment ${ }^{29}$. These costs appeared to remain true after consideration was taken for the cohort's chronic disease status as measured by the chronic disease score. In addition the severity of sleep-disordered breathing (as measured by the apnoea-hypopnoea index) was directly related to the healthcare costs used by those groups ${ }^{29}$. A similar two-fold increase in healthcare consumption was demonstrated in terms of hospital stay and physician claims two years prior $^{30}$, and ten years prior to diagnosis ${ }^{31}$ in further studies.

Hillman et al went one step further and comprehensively evaluated the direct costs of sleep disorders (those incurred through the health system including co-morbidities from appropriate attributable fractions), indirect costs (motor vehicle accidents, workrelated injuries and lost productivity), and nonfinancial costs derived from depreciated quality of life and premature death ${ }^{32}$. The estimated total economic cost of sleep disorders in an Australian population of 20.1 million (in the year 2004) was $\$ 7.5$ US billion, and the equivalent cost for a population the size of the USA was around \$109US billion ${ }^{32}$.

Direct costs contribute less than $2 \%$ of the total cost of sleep disorders, whilst indirect and financial expenses account for a disproportionately larger share of the total $\operatorname{cost}^{32}$. This reflects a lack of revenue allocated to prevention, diagnosis and treatment of sleep apnoea. It also demonstrates the often underestimated ripple effect that sleep disorders can have on the psychosocial and economic fronts.

The high cost of sleep apnoea is matched by a higher cost-effectiveness when considering standard treatment with CPAP. Using models to represent the natural history of OSAS, Mar et al compared the cost of nasal continuous positive airway pressure (nCPAP) treatment versus the alternative of allowing OSAS to take its untreated course ${ }^{33}$. It was shown that nCPAP has a costeffectiveness in line with commonly funded healthcare initiatives such as antihypertensive drug therapy, the benefits largely derived from improved daytime alertness and quality of life ${ }^{33}$. For those with OSAS who remain adherent to their CPAP treatment after two years, there appears to be an absolute reduction in direct costs from physician consultation costs and hospital stays ${ }^{34}$.

Central to the model of cost-effectiveness is an acceptable degree of compliance to treatment. Whilst technical reasons for non-compliance are pervasive, Suri et al has outlined some socio-cultural considerations applicable to the Indian patient. Initial refusal of therapy is higher, and significantly fewer patients were able to source their CPAP devices from insurance / healthcare funds $s^{35}$. In addition, regular CPAP use in India was impeded by more hostile weather conditions, frequent travel, inconsistent power supply, and issues relating to privacy ${ }^{35}$.

Indian Journal of Sleep Medicine (IJSM), Vol. 4, No. 3, 2009 
Adherence to CPAP treatment is economically advantageous when taking into consideration the gains in quality of life, costs of therapy, and outcomes from motor vehicle accidents ${ }^{14}$. The conversion of these physical sequelae of sleep apnoea into economic terms will hopefully allow developed and developing communities alike to account for future workforce planning and resource allocation.

\section{Summary}

Sleep apnoea is a common condition with far-reaching implications for social and psychosocial functioning. Through sleep deprivation and neurocognitive deficits, sleep apnoea can be a contributor to motor vehicle accidents and occupational injuries. Disrupted sleep, quality of life and depression are all intimately associated. Treatment with CPAP has demonstrated benefits in reducing motor vehicle accidents and occupational injury, subjective quality of life scales and subjective depression scales. The human consequences of untreated sleep apnoea can be consistently translated into economic terms that may be useful on social planning platforms. The economic impact of untreated sleep apnoea is present well before diagnosis and initiation of treatment, and its social impact is underappreciated as evidenced by the disproportionately large indirect cost component. Adherence to CPAP therapy for sleep apnoea is cost effective and economically advantageous.

\section{References}

1. Young T, Palta M, Dempsey J, Skatrud J, Weber S, Badr S. The occurrence of sleep-disordered breathing among middle-aged adults. N Engl J Med 1993; 328(17):12301235 .

2. Udwadia ZF, Doshi AV, Lonkar SG, Singh CI. Prevalence of sleep-disordered breathing and sleep apnea in middle-aged urban Indian men. Am J Respir Crit Care Med 2004; 169:168-73.

3. Sharma SK, Kumpawat S, Banga A, Goel A. Prevalence and risk factors of obstructive sleep apnea syndrome in a population of Delhi, India. Chest 2006; 130(1):14956.

4. Ohayon MM, Guilleminault C, Priest RG, Caulet M. Snoring and breathing pauses during sleep: telephone interview survey of United Kingdom population sample. BMJ 1997; 314:860-863.

5. Sateia MJ. Neuropsychological impairment and quality of life in obstructive sleep apnea. Clin Chest Med 2003; 24(2):249-59.

6. Schneider C, Fulda S, Schulz H. Daytime variation in performance and tiredness/sleepiness ratings in patients with insomnia, narcolepsy, sleep apnea and normal controls. J Sleep Res 2004; 13(4):373-383.

7. Gast H, Schwalen S, Ringendahl H, Jörg J, Hirshkowitz M. Sleep-Related Breathing Disorders and Continuous Positive Airway Pressure-Related Changes in Cognition. Sleep Med Clin 2006; 1(4):499-511.

8. NHTSA Traffic Safety Fact Sheet, Alcohol-Impaired Driving. 2007 Data. DOT HS 810 985. Accessed www.nhtsa.gov, 03/03/2009.

9. NHTSA Overview Traffic Safety Fact Sheet, 2007. DOT HS 810 993. Accessed www.nhtsa.gov, 03/03/2009.

10. George CF. Sleep apnea, alertness, and motor vehicle crashes. Am J Respir Crit Care Med 2007; 176(10):954-6.

11. Howard ME, Desai AV, Grunstein RR, et al. Sleepiness, sleep-disordered breathing, and accident risk factors in commercial vehicle drivers. Am J Respir Crit Care Med 2004; 170(9): 1014-1021.

12. Gururaj G. Road traffic deaths, injuries and disabilities in India:current scenario. Natl Med J India 2008; 21 (1):14-20

13. George CF. Reduction in motor vehicle collisions following treatment of sleep apnoea with nasal CPAP. Thorax 2001; 56:508-512.

14. Ayas NT, Fitzgerald M, Fleetham JA, et al. Cost-effectiveness of continuous positive airway pressure therapy for moderate to severe obstructive sleep apnea/hypopnea. Arch Intern Med 2006; 166:977-984.

15. Ulfberg J, Carter N, Edling C. Sleep-disordered breathing and occupational accidents. Scand J Work Environ Health $2000 ; 26: 237-242$.

16. Lindberg E, Carter N, Gislason T, Janson C. Role of snoring and daytime sleepiness in occupational accidents. Am J Respir Crit Care Med 2001; 164:2031-2035.

17. Sjösten $\mathbf{N}$, Kivimäki $M$, Oksanen $T$, et al. Obstructive sleep apnoea syndrome as a predictor of work disability. Respir Med 2009; Feb 24. [Article in press]

18. Akashiba T, Kawahara S, Akahoshi T, et al. Rela-tionship between quality of life and mood or depres-sion in patients with severe obstructive sleep apnea syndrome. Chest 2002; $122: 861-865$.

19. Sforza E, de Saint Hilaire Z, Pelissolo A, Rochat T, Ibanez V. Personality, anxiety and mood traits in patients with sleeprelated breathing disorders: Effect of reduced daytime alertness. Sleep Med 2002;3:139-145.

20. Weaver TE, Laizner AM, Evans LK, et al. An instrument to measure functional status outcomes for disorders of excessive sleepiness. Sleep 1997; 20(10):835-43

21. Yue W, Hao W, Liu P, Liu T, Ni M, Guo Q. A case-control study on psychological symptoms in sleep apnea hypopnea syndrome. Can J Psychiat 2003; 48:318-23.

22. Millman RP, Fogel BS, McNamara ME, Carlisle CC. Depression as a manifestation of obstructive sleep apnea: reversal with nasal continuous positive airway pressure. $J$ Clin Psychiatry 1989; 50(9):348-51.

23. Deldin PJ, Phillips LK, Thomas RJ. A preliminary study of 
sleep-disordered breathing in major depressive disorder. Sleep Med 2006; 7:131-9.

24. Sánchez Al, Martínez P, Miró E, Bardwell WA, Buela-Casal G. CPAP and behavioral therapies in patients with obstructive sleep apnea: Effects on daytime sleepiness, mood, and cognitive function. Sleep Med Rev 2009; Feb 7 [Article in press]

25. Ohayon $\mathbf{M} \mathbf{M}$. The effects of breathing-related sleep disorders on mood disturbances in the general population. J Clin Psychiatry 2003; 64(10):1195-200

26. Peppard PE, Szklo-Coxe M, Hla KM, Young T. Longitudinal Association of Sleep-Related Breathing Disorder and Depression. Arch Intern Med 2006; 166(16):1709-15

27. Sharafkhaneh A, Giray N, Richardson P, Young T, Hirshkowitz M. Association of psychiatric disorders and sleep apnea in a large cohort. Sleep 2005; 28:1405-11

28. Giles TL, Lasserson TJ, Smith BH, White J, Wright J, Cates CJ. Continuous positive airways pressure for obstructive sleep apnoea in adults. Cochrane Database Syst Rev 2006; 3:CD001106.

29. Kapur V, Blough DK, Sandblom RE, et al. The medical cost of undiagnosed sleep apnea. Sleep 1999; 22(6):749-55.
30. Kryger MH, Roos L, Delaive K, Walld R, Horrocks J. Utilization of health care services in patients with severe obstructive sleep apnea. Sleep 1996; 19(9):s 111 -s 116.

31. Ronald J, Delaive K, Roos L, Manfreda J, Bahammam A, Kryger MH. Health Care Utilization in the 10 Years Prior to Diagnosis in Obstructive Sleep Apnea Syndrome Patients. Sleep 1999; 22(2):225-9

32. Hillman D, Murphy A, Pezzullo L. The economic cost of sleep disorders. Sleep 2006; 29:299-305

33. Mar J, Rueda JR, Duran-Cantolla J, Schechterz C, Chilcott J. The cost-effectiveness of nCPAP treatment in patients with moderate-to-severe obstructive sleep apnoea. Eur Respir J 2003; $21: 515-522$

34. Bahammam A, Delaive K, Ronald J, Manfreda J, Roos L, Kryger MH. Health Care Utilization in Males with Obstructive Sleep Apnea Syndrome Two Years After Diagnosis and Treatment. Sleep 1999; 22(6):740-7

35. Suri JC, Sen MK, Ojha UC. Acceptance and compliance issues of nasal CPAP amongst Indian patients of obstructive sleep apnea. Indian J Sleep Medicine 2006; $1.4,197-203$ 